\title{
The apparent disappearance of Loligo forbesi from the south of its range in the 1990s: Trends in Loligo spp. abundance in the northeast Atlantic and possible environmental influences
}

\author{
C.S. Chen ${ }^{a^{*}}$, G.J. Pierce ${ }^{a}$, J. Wang ${ }^{a}$, J.-P. Robin ${ }^{b}$, J.C. Poulard ${ }^{c}$, J. Pereira ${ }^{d}$, A.F. Zuure, \\ P.R. Boyle ${ }^{a}$, N. Bailey ${ }^{f}$, D.J. Beare ${ }^{f}, 1$, P. Jereb ${ }^{g}$, S. Ragonese ${ }^{h}$, A. Mannini $^{i}$ and L. Orsi-Relini ${ }^{i}$ \\ ${ }^{\mathrm{a}}$ School of Biological Sciences, University of Aberdeen, Tillydrone Avenue, Aberdeen AB24 2TZ, UK \\ b Laboratoire de Biologie et Biotechnologies Marines, I.B.F.A., Université de Caen, Esplanade de la Paix, 14032 \\ Caen Cedex, France \\ 'IFREMER, Département Ecologie et Modèles pour l'Halieutique (EMH), rue de l'lle d'Yeu, BP21105, F-44311 \\ Cedex 03, Nantes, France \\ dIPIMAR, Avenida de Brasília, S/N, 1449-006 Lisbon, Portugal \\ eHighland Statistics Ltd., 6 Laverock Road, Newburgh, Aberdeenshire AB41 6FN, UK \\ ${ }^{f}$ Fisheries Research Services, The Marine Laboratory, P.O. Box 101, Victoria Road, Aberdeen AB11 9DB, UK \\ ICRAM, Via di Casalotti 300, 00166 Roma, Italy \\ h Institute for Coastal Marine Environment, Section of Mazara del Vallo, Via Luigi Vaccara, 61 - 91026 Mazara del \\ Vallo Trapani, Italy \\ 'Laboratorio di Biologia Marina ed Ecologia Animale del Dip. Te. Ris (DIPTERIS), Università di Genova, Via Balbi \\ 5, 16126 Genova, Italy \\ *: Corresponding author : 1, Sec. 4, Roosevelt Road, Taipei 10617, Taiwan. \\ Present address: Institute for the Protection of the Citizen (IPSC), European Commission, Joint Research Centre, \\ I-21020 Ispra (VA), Italy. ccshin@ntu.edu.tw
}

\begin{abstract}
Since the early 1990s, Loligo forbesi has apparently disappeared from much of the southern part of its former range, with catches off the Iberian Peninsula, for example, declining dramatically during the 1990s. The present paper assembles data from fishery and research cruise databases to examine the evidence for a shift in distribution, examine the relationship between abundance of this species and that of the partially sympatric Loligo vulgaris, and identify possible environmental correlates. Time-series of abundance of L. forbesi and L. vulgaris were assembled using fishery and survey data from Scotland, France, and Portugal. Based on availability of data and timing of the main fishery, data for autumn (October-December) were selected. Nine squid series and two explanatory variables (October sea surface temperature and the winter NAO index) were analysed using dynamic factor analysis (DFA). The optimal DFA model contained two common trends and both of the explanatory variables. The first common trend shows an increase from 1987 to 1999, and a slight decrease after 2000 onwards, and is positively related to $L$. forbesi abundance in the north of its range (Scotland), while negatively related to squid abundance (both species) in the south of their ranges (France and Portugal). The second trend identifies an increase from 1990 to 1995, followed by a decrease until 2002, and is positively related to the squid (L. forbesi and L. vulgaris) abundance series from French surveys and fisheries. The SST series was significantly related to three squid abundance series: positively with abundance of small L. forbesi in French surveys and negatively with the abundance of small $L$. forbesi from Scottish surveys and abundance of $L$. vulgaris in Portuguese surveys. The winter NAO series was significantly related to the abundance of small L. forbesi from Scottish surveys. The increase in SST after 1993 and subsequent high level may thus be associated with the decrease of Loligo abundance in the south area (France and Portugal) and the increase in Loligo abundance in the north area (Scotland).
\end{abstract}

Keywords: Loligo; Squid fishery; Abundance; Common trends; Dynamic factor analysis; North Atlantic Oscillation (NAO) 
The apparent disappearance of Loligo forbesi from the south of its range in the 1990s: trends in Loligo spp. abundance in the northeast Atlantic and possible environmental influences

\author{
C.S. Chen ${ }^{a^{*}}$, G.J. Pierce ${ }^{a}$, J. Wang ${ }^{a}$, J.-P. Robin ${ }^{b}$, J.C. Poulard ${ }^{c}$, \\ J. Pereira ${ }^{\mathrm{d}}$, A.F. Zuur ${ }^{\mathrm{e}}$, P.R. Boyle ${ }^{\mathrm{a}}$, N. Bailey ${ }^{\mathrm{f}}$, D.J. Beare ${ }^{\mathrm{f}}$, \\ P. Jereb $^{\mathrm{g}}$, S. Ragonese ${ }^{\mathrm{h}}$, A. Mannini ${ }^{\mathrm{i}}$ and L. Orsi-Relini ${ }^{\mathrm{i}}$
}

${ }^{\mathrm{a}}$ School of Biological Sciences, University of Aberdeen, Tillydrone Avenue, Aberdeen AB24 2TZ, UK

${ }^{\mathrm{b}}$ Laboratoire de Biologie et Biotechnologies Marines, I.B.F.A., Université de Caen, Esplanade de la Paix, 14032 Caen Cedex, France

'IFREMER, Département Ecologie et Modèles pour l'Halieutique (EMH), rue de l'Ile d'Yeu, BP21105, F-44311 Cedex 03, Nantes, France

${ }^{\mathrm{d}}$ IPIMAR, Avenida de Brasília, S/N, 1449-006 Lisbon, Portugal

${ }^{\mathrm{e}}$ Highland Statistics Ltd, 6 Laverock Road, Newburgh, Aberdeenshire, AB41 6FN, UK

${ }^{\mathrm{f}}$ Fisheries Research Services, The Marine Laboratory, PO Box 101, Victoria Road, Aberdeen, AB11 9DB, UK

${ }^{\mathrm{g}}$ ICRAM, Via di Casalotti 300, 00166 Roma, Italy

h Institute for Coastal Marine Environment, Section of Mazara del Vallo, Via Luigi Vaccara, 61 - 91026 Mazara del Vallo Trapani, Italy

${ }^{\mathrm{i}}$ Laboratorio di Biologia Marina ed Ecologia Animale del Dip. Te. Ris (DIPTERIS), Università di Genova, Via Balbi 5, 16126 Genova, Italy

* Corresponding author. Present address: 1, Sec. 4, Roosevelt Road, Taipei 10617, Taiwan.

E-Mail address: ccshin@ntu.edu.tw (C.S. Chen).

\begin{abstract}
Since the early 1990s, Loligo forbesi has apparently disappeared from much of the southern part of its former range, with catches off the Iberian Peninsula, for example, declining dramatically during the 1990s. The present paper assembles data from fishery and research cruise databases to examine the evidence for a shift in distribution, examine the relationship between abundance of this species and that of the partially sympatric L. vulgaris, and identify possible environmental correlates. Time-series of abundance of $L$. forbesi and $L$. vulgaris were assembled using fishery and survey data from Scotland, France, and Portugal. Based on availability of data
\end{abstract}


and timing of the main fishery, data for autumn (October-December) were selected. Nine squid series and two explanatory variables (October sea surface temperature and the winter NAO index) were analysed using dynamic factor analysis (DFA). The optimal DFA model contained two common trends and both of the explanatory variables. The first common trend shows an increase from 1987-1999, and a slight decrease after 2000 onwards, and is positively related to L. forbesi abundance in the north of its range (Scotland), while negatively related to squid abundance (both species) in the south of their ranges (France and Portugal). The second trend identifies an increase from 1990-1995, followed by a decrease until 2002, and is positively related to the squid (L. forbesi and $L$. vulgaris) abundance series from French surveys and fisheries. The SST series was significantly related to three squid abundance series: positively with abundance of small $L$. forbesi in French surveys and negatively with the abundance of small $L$. forbesi from Scottish surveys and abundance of $L$. vulgaris in Portuguese surveys. The winter NAO series was significantly related to the abundance of small L. forbesi from Scottish surveys. The increase in SST after 1993 and subsequent high level may thus be associated with the decrease of Loligo abundance in the south area (France and Portugal) and the increase in Loligo abundance in the north area (Scotland).

Key words: Loligo, squid fishery, abundance, common trends, dynamic factor analysis, North Atlantic Oscillation (NAO).

\section{Introduction}

The veined squid, Loligo forbesi Streenstrup, 1856, and European squid, L. vulgaris Lamarck, 1798, are two important squid fishery resources in the north Atlantic. The most important commercial catches are taken by UK, France, Spain and Portugal (Boyle and Pierce, 1994).

The range of these two Loligo species in the northeast Atlantic is largely overlapping, with $L$. forbesi occurring throughout the northeast Atlantic between $20^{\circ}-63^{\circ} \mathrm{N}$, and $L$. vulgaris between $20^{\circ}-55^{\circ} \mathrm{N}$ (Guerra and Rocha, 1994). However, L. forbesi is more abundant in the northern part of its range, while L. vulgaris dominates the southern part of its range and is effectively absent from catches in Scottish waters (Pierce et al., 1994a, b).

These squid are mainly landed as by-catch of multi-species demersal trawling fisheries (Cunha and Moreno, 1994; Guerra et al., 1994; Pierce et al., 1994a). 
However, directed artisanal fishing is important on the Atlantic coasts of Spain and Portugal and in the Mediterranean. Within UK waters, there is limited directed fishing at Rockall Bank (mainly the 1980s), in the English Channel, and in the Moray Firth (Pierce et al., 1994a; Young et al., this volume).

Fishery statistics do not distinguish these two species, since they are of similar appearance and equal commercial value. However, landing in the Scottish waters can generally assumed to be L. forbesi (Pierce et al., 1994a, b), while in the Mediterranean L. vulgaris is practically the only species landed (Guerra et al., 1994). Annual landings of $L$. forbesi in the Scotland have ranged from $82-1854$ tonnes in the past three decades. In France, Loligo spp. is the second most important fished cephalopod, after cuttlefish. Annual landings of Loligo in France ranged from 3711 - 6576 tonnes during 1989-2002. Landings of Loligo in Portugal ranged 310 - 1870 tonnes annually in 1986-1997, Octopus vulgaris being the most important fished cephalopod (Anon., 2002).

Abundance trends, movements and distribution patterns of $L$. forbesi in UK waters have previously been shown to be related to environmental conditions, particularly water temperature (Pierce et al., 1998; Waluda and Pierce, 1998; Bellido et al., 2001; Sims et al., 2001; Pierce and Boyle, 2003; Zuur and Pierce, 2004). Robin and Denis (1999) examined fluctuations in abundance of loliginid squid stock in the English Channel, based on fishery statistics from the UK and France, and showed that squid cohort strength is related to water temperature, especially to winter temperature. Analyses of catch rates of Loligo by French commercial trawlers showed that SST in April and July had a significant effect on squid distribution and inter-annual changes (Denis et al., 2002). There are fewer studies on distribution and abundance Loligo spp. in the southern part of their range, although trends in landings from Spanish and Portuguese Loligo fisheries were described by Guerra et al. (1994) and Cunha and Moreno (1994), respectively. However, an overview on abundance trends across the distribution regions of $L$. forbesi and $L$. vulgaris is still lacking.

The particular interest in larger-scale variation arises from the apparent disappearance of $L$. forbesi from commercial landings in Spain and Portugal during the early part of the 1990s (see Boyle and Pierce, 1994). Furthermore, as highlighted by Anon. (2002), during the 1990s, cephalopod landings in the Mediterranean generally declined, in contrast to an increasing trend in overall cephalopod landings from the NE Atlantic. This leads to several questions: was the decline in abundance consistent across a wide area, has the decline been sustained or has the stock recovered, has there been a 
concurrent rise in the abundance of $L$. vulgaris, and can these trends be related to changes in environmental conditions? Many studies have indicated changes in abundance and species composition in marine communities associated with a general warming of the northern Northeast Atlantic.

Dynamic factor analysis (DFA) is a dimension-reduction technique for processing time series. DFA can be used to model relatively short, non-stationary time series in terms of common patterns and explanatory variables (Zuur et al., 2003a). In this study, we compile fishery and survey data of Loligo spp. in the northeast Atlantic from Scotland, France, and Portugal to quantify abundance trends for $L$. forbesi and $L$. vulgaris in the northeast Atlantic, and their relationships with indices of marine climate.

\section{Materials and methods}

\subsection{Squid data}

The squid data used in this study included fishery and survey data from Scotland (UK), France and Portugal, thus essentially covering the entire north-south extent of the range of Loligo forbesi in Atlantic coastal waters. The fishery and survey data for Scotland were extracted from databases held at Fisheries Research Services Marine Laboratory. The fisheries data consist of monthly average trawler landings per unit effort (LPUE) of squid (assumed to be $L$. forbesi) for the two ICES subdivisions IVa (northern North Sea) and VIa (west coast of Scotland) from 1970-2000. Loligo is mainly a by-catch of the whitefish fishery in Scottish waters and fishing effort is assumed to be independent of squid abundance. The relatively high value of squid means discarding is minimal (Young et al., 2004). Hence, we assume that LPUE is equivalent to CPUE and will be a reasonable index of abundance (Pierce and Boyle, 2003). The survey data ranged $7^{\circ} 25^{\prime} \mathrm{E}-16^{\circ} 12^{\prime} \mathrm{W}, 48^{\circ} 04^{\prime}-62^{\circ} 08^{\prime} \mathrm{N}$ during 1963-2004. Surveys took place in most calendar months, with the best coverage being for February $(n=28$ yrs), March $(n=25)$, August $(n=27)$, and November $(n=26)$. For comparability with the fishery data set, we extracted the Loligo catch data from hauls within ICES subdivision IVa and VIa for further analysis.

French Loligo landings data were provided by the Centre Administratif des Affaires Maritimes St Malo (CAAM) for the period of 1989-2002. Since both $L$. forbesi and $L$. vulgaris are present in French waters and landings are not identified to species, we used the LPUE of Loligo spp. for further analysis. French survey data, from the EVHOE bottom trawl surveys, were extracted from a database held by the French 
Research Institute for Exploitation of the Sea (IFREMER). The survey was carried every year since 1987 on the eastern continental shelf of the Bay of Biscay. The survey periods were May-June in 1988 and 1991 and September-December during 1987-2003 (except 1991, 1993 and 1996). Squid were identified to species level, so that CPUE was available for both $L$. forbesi and L. vulgaris.

Fishery and survey data from Portugal were extracted from databases held by the Instituto de Investigação das Pescas e do Mar (IPIMAR). Fishery data consisted of monthly catch and LPUE for Loligo spp. from 1988-1996. The survey data came from the area $10^{\circ} 02^{\prime}-7^{\circ} 16^{\prime} \mathrm{W}, 36^{\circ} 25^{\prime}-42^{\circ} 34^{\prime} \mathrm{N}$ from $1990-2002$. Surveys took place in most months but the best coverage was for July $(n=13$ yrs), October $(n=20)$, and November $(n=18)$. The squid were identified to the species level, so that CPUE was available for both $L$. forbesi and $L$. vulgaris.

The localities of survey catches, pooled by ICES statistical rectangle (i.e. with a spatial resolution of $1^{\circ}$ longitude by $0.5^{\circ}$ latitude), from the three countries are presented in Fig. 1. For the complete of data set by year in each country, we chose the autumn months (October - December) for further analysis. Based on the fishery data from these three countries, the autumn catch accounts for around $40 \%$ of total annual catch. This is also the main period of recruitment to the fishery (Boyle and Pierce, 1994).

In all cases, the abundance index was based on the weight of squid caught per hour of fishing, using an overall value calculated as the sum of catches in all hauls during each autumn season divided by the sum of hours fishing.

In a preliminary analysis of the biological data of squid, two modes were found in the mantle length (ML) composition of L. forbesi from the French surveys. Accordingly, the data on squid from Scottish and French surveys were separated into small-sized and large-sized components (divided at $150 \mathrm{~mm}$ mantle length (ML), which corresponds approximately to the size at which the species is fully recruited to the fishery: see Pierce et al., 1994b). Small-sized L. forbesi are numerically dominant in both countries, comprising $75 \%$ (by number) of the total survey catches of the species in Scotland and $70 \%$ in France. The CPUE for L. forbesi collected by Portuguese surveys was not divided by size due to small sample sizes. The ML frequency distribution for L. vulgaris was uni-modal so no division of the data was applied. The final time series of squid CPUE or LPUE used in this study are shown in Table 1. 


\subsection{Explanatory variables}

Reynolds sea surface temperature (SST) data were downloaded from the National Center for Atmospheric Research, USA (NCAR) website. The data are monthly average model results from remotely sensed data, survey temperature data, and sea ice distribution, with a spatial resolution of $1^{\circ}$ longitude by $1^{\circ}$ latitude (Reynolds and Smith, 1994). The data were re-sampled to the ICES statistical rectangle spatial resolution of $1^{\circ}$ longitude by $0.5^{\circ}$ latitude (Wang et al., 2003). Monthly SST time series were extracted for arbitrarily selected locations off the coasts of Scotland, France and Portugal (Fig. 1): 40E4 $\left(5.5^{\circ} \mathrm{W}, 55.75^{\circ} \mathrm{N}\right)$ and $46 \mathrm{E} 6\left(3.5^{\circ} \mathrm{W}, 58.75^{\circ} \mathrm{N}\right)$ for Scotland, 24E5 $\left(4.5^{\circ} \mathrm{W}, 47.75^{\circ} \mathrm{N}\right)$ and 32E2 $\left(7.5^{\circ} \mathrm{W}, 51.75^{\circ} \mathrm{N}\right)$ for France, and 06E0 $\left(9.5^{\circ} \mathrm{W}, 38.75^{\circ} \mathrm{N}\right)$ for Portugal. For the autumn period (October - December) the three monthly SST time series were significantly correlated with each other. Hence we used the SST time series of October for further analysis. Preliminary analysis also indicated that October SST for a single rectangle was very similar to the average SST for the block of nine adjacent ICES rectangles with the single rectangle in the centre.

In a further preliminary analysis, dynamic factor analysis (described below) was applied to these five October SST time series. Results indicated that all these time series could be described by two common trends. Point 06E0 was most important to trend 1, while 40E4 was most important to trend 2. Therefore, we used the SST time series from these two points as explanatory variables for further analysis, denoting the 06E0 SST as "SST_south", and the 40E4 series as "SST_north".

Another explanatory variable used in the analysis is the winter North Atlantic Oscillation (NAO) index (Hurrell, 1995). This index is defined as the difference on the normalised sea level (atmospheric) pressures (SLPs) between Ponta Delgada (Azores) and Stykkisholmur / Reykjavik (Iceland). A higher index indicates strong westerly winds; a lower index indicates weak westerly winds. The "winter" index for a given year is the average of monthly values for (the previous) December through to February. The winter NAO index data were obtained from the Climate and Global Dynamics Division of The National Center for Atmospheric Research (NCAR) website (http://www.cgd.ucar.edu/cas/jhurrell/indices.html).

\section{Dynamic factor analysis}

Dynamic factor analysis (DFA) is a multivariate time-series analysis technique used to 
estimate underlying common trends in a set of time series. The DFA model can be written as:

$$
y_{t}=A \times z_{t}+B \times x_{t}+e_{t}
$$

where: $y_{t}$ is a matrix containing the value of the $N$ time series at time $t$, $\mathbf{z}_{t}$ is a matrix containing the values of the $M$ common trends at time $t$, A contains the factor loadings (an $N \times M$ matrix), $\mathbf{x}_{t}$ is a matrix containing values for the explanatory variables, $\boldsymbol{B}$ contains regression parameters for each explanatory variable, $\boldsymbol{e}_{\boldsymbol{t}}$ are the noise components.

It is assumed that $e_{\mathrm{t}} \sim N(0, \boldsymbol{R})$, where $\boldsymbol{R}$ is the error covariance matrix. The magnitude and sign of the factor loadings $(\boldsymbol{A})$ determines how these trends are related to the original time series. The regression parameters $(B)$ and their standard errors indicate the influence of the explanatory variables on the time series.

There are two options for the modelling of $\boldsymbol{R}$. One approach is to use a diagonal matrix. Another approach is to use a symmetric, non-diagonal matrix. The elements of a non-diagonal $\boldsymbol{R}$ matrix represent the information that cannot be explained by the common trends and explanatory variables.

For $M$ time series, DFA can be applied in various forms, with $N$ common trends $(1 \leq N$ $<M$ ), with and without explanatory variables and constant parameters; models with a diagonal or non-diagonal error covariance matrix $\boldsymbol{R}$. Zuur et al. (2003a, b) suggested that the Akaike information criterion (AIC) could be used for model selection. The AIC is a function of the measure of fit (maximum likelihood) and the number of parameters (number of trends, explanatory variables and structure of matrix $\boldsymbol{R}$ ). In this paper, the DFA model with the smallest AIC value is taken to be the 'best' candidate model. DFA was performed using the software package Brodgar version 2.3.4 (Highland Statistics Ltd, http://www.brodgar.com).

The available time periods of the Portuguese LPUE series were too short to include in the DFA model. Therefore, we used the other nine squid abundance series for further analysis. Four types of DFA models were used to estimate the underlying common trends (Table 2). Type 1 models described the nine squid abundance series using a constant, a linear combination of $M$ common trends, and a noise term, with the assumption of normal distribution with an expectation (mean) of 0 and a diagonal error covariance matrix $\boldsymbol{R}$. Models with 1, 2 and 3 common trends are denoted as 1a, $1 \mathrm{~b}$ and $1 \mathrm{c}$ respectively. Type 2 models are the same as type 1 models, but with 
explanatory variables (SST \& NAO) added in different combinations. Type 3 and 4 models are the same as types 1 and 2 respectively, except that a positive definite, symmetric non-diagonal was assumed for the error covariance matrix.

Relationships with environmental variables identified from DFA model were explored further to determine whether there were time-lagged effects, using a combination of simple correlation and cross-correlation analyses. Simple correlations were calculated between monthly SST series and estimated common trends. In the case of winter NAO index series, since monthly series are difficult to interpret, cross-correlations between common trends and winter NAO index (December to February) were determined, i.e. to detect time-lagged effects on a yearly scale.

\section{Results}

The original CPUE and LPUE series showed large interannual fluctuations. We used square-rooted transformation of original data to reduce the effect of extreme years. Each of the CPUE and LPUE series was standardised by subtracting its mean and divide by the standard deviation. As a result, each series was centred around zero, had unit variance and was unit-less. This process ensures that the all time series are on the same scale. The standardised squid CPUE and LPUE series are presented in Fig. 2. There seems to be a similar variation pattern for different species in each geographical location.

The explanatory variables, SST_north, SST_south and the winter NAO index, are shown in Fig. 3. In a preliminary analysis, these three explanatory variables were included in the DFA model. When added as a single explanatory variable in the model, the AIC values were 481.4 for NAO, 498.1 for SST_north, and 499.0 for SST_south, respectively. When added as two explanatory variables into the model, the AIC values were 410.3 for NAO \& SST_north, 448.0 for NAO \& SST_south, and 482.2 for SST_north \& SST_south, respectively. No common trend was found when using all three explanatory variables in the model. The model containing both SST values was thus less satisfactory than models containing only one SST value. In addition, although collinearity between the two SST series was not high $(\mathrm{r}=0.48, \mathrm{~N}=21, P<$ 0.05), models containing both SST variables appeared to be unstable. Therefore we used only SST_north and the winter NAO index as explanatory variables in the final models.

The AIC value of each model is shown in Table 3. The AIC values indicated that a 
model with two common trends, and (October) SST and winter NAO index as explanatory variables, under a non-diagonal error covariance matrix, was the optimal model (4e in Table 3).

The estimated common trends are shown in Fig. 4. The order of the common trends in a DFA model is not related to their importance. However, the shape of common trends in a model with a single common trend (not illustrated) is very similar to the first common trend (Fig. 4), which suggests that the first common trend is the most important one. The first common trend shows a stable status during 1977-1986 and a rather dramatic increase from 1987-1999, with a decreasing trend after 2000. The canonical correlations between the original squid abundance series and the estimated trends indicate that the first common trend is positively correlated with the series of squid abundance in the north region (Sc_Lf_S, Sc_Lf_L, Sc_LPUE), but also with Fr_Lf_S, and negatively correlated with most of the squid abundance series in the south regions (Fr_Lf_L, Fr_Lv, Fr_LPUE, Pt_Lf, and Pt_Lv). In other words, this trend represents a general increase in abundance of Loligo spp. in the north, and a general decline in the south. The interpretation is complicated by opposite trends for large and small $L$. forbesi in France. It should also be noted that trends in both Loligo species in Portugal were similar.

The second common trend shows a slight decrease between 1977 and 1990, an increase until 1995, followed by a decrease until 2002 (Fig. 4). This second trend is positively related to the squid abundance in the south regions, though only significant for Fr_Lf_L, Fr_Lv, and Fr_LPUE, and negatively related to the squid abundance in the north region, being significant for Sc_LPUE. Thus, this appears to mainly reflect a higher abundance of L. vulgaris in French waters in the mid 1990s and the lower abundance of $L$. forbesi in Scottish waters during the same period. The fitted curves for the optimum model are presented in Fig. 5. The Portuguese commercial LPUE series (not used in the model) is also shown for comparison.

The residuals plots for model fitting for each squid series are shown in Fig. 6. The normality of residual distribution indicated a good fit for the estimated model, particularly for longer series such as the Scottish squid data.

The time-series for SST was characterised by a decreasing trend during 1989-1993, and an increase in 1994-1995, following which SST remained at higher levels than in the 1980s (SST_north in Fig. 3). The estimated regression parameters and t-values for the SST and winter NAO series from the DFA model are shown in Table 4. The SST 
series is significantly related to three squid abundance series: positively with Fr_Lf_S and negatively with Sc_Lf_S and Pt_Lv. The winter NAO series was positively related to Sc_Lf_S (Table 4; note that a t-value of approximately 2.0 is significant at the 5\% level). Thus abundance of small (pre-recruit) L. forbesi in the north of its range appears to be higher in years with lower autumn SST, while in French waters, $L$. forbesi abundance is positively related to autumn SST.

The two calculated common trends in squid abundance were compared with monthly SST series (SST at ICES rectangle $40 \mathrm{E} 4 ; 5.5^{\circ} \mathrm{W}, 55.75^{\circ} \mathrm{N}$ ) to examine possible lagged SST effects on autumn squid abundance. Spearman's correlation coefficients indicate that SST series for February to May and August to November are all positively significant related with trend $1(P<0.05$; Table 5$)$, and SST series for February to June are all significantly negatively related with trend 2.

The cross-correlation functions between squid abundance common trends and environmental variables are shown in Fig. 7. Cross-correlations calculated between SST and common trend 1 (positive lag, SST leading squid trend, 1 to 5 yrs) indicated a positive correlation at a lag of 1-2 yr. Cross-correlation between SST and common trend 2 (positive lag, SST leading squid trend, 1 to $5 \mathrm{yrs}$ ) showed a negative correlation at a lag of 1-3 yrs.

No significant correlation was found between the winter NAO index and trend 1 (Fig. 7 lower left; positive lag, NAO leading squid trend, 1 to $5 \mathrm{yrs}$ ), or winter NAO index and trend 2 (Fig. 7 lower right; positive lag, NAO leading squid trend, 1 to 5 yrs).

For comparison with the above results, we also fitted a DFA model using SST_S and winter NAO index as explanatory variables. In this case, the AIC value suggested that model with single common trend was the optimal one (with the lowest AIC value). This common trend (not illustrated) was broadly similar to that obtained previously, showing a generally increasing pattern, was positively correlated to Loligo abundance in the north. We also fitted a model with two common trends and this also presented a similar pattern to the common trends reported for our optimal model.

\section{Discussion}

In this study, we compiled fishery and survey data from Scotland, France, and Portugal to examine abundance trends for Loligo forbesi and L. vulgaris across their range in the northeast Atlantic and their possible relationships with two environmental 
variables. The calculated common trends suggested a general decline of $L$. forbesi in Portuguese and French waters, alongside an increase in Scottish waters. The SST and winter NAO index were used as explanatory variables in the optimal DFA model, and the lagged effect of SST could play a role in controlling the temporal variation of squid abundance (c.f. Pierce and Boyle, 2003; Zuur and Pierce 2004).

The normality of data series is not an essential criterion for linear regression models (Quinn and Kenough, 2002). However, it would be beneficial for DFA models (Zuur et al., 2003b). The catches of squid fisheries are characterised large annual fluctuation, which could result at least in part from environmental variability (Bakun and Csirke, 1998). In this study, we square-root transformed the data series in the DFA model to reduce the influence of extreme values. The residual plots (Fig. 6) suggested a good fit to the model for longer time series of squid abundance, though less satisfactory for shorter data series.

Using a critical size (around $15 \mathrm{~cm} \mathrm{ML)} \mathrm{to} \mathrm{define} \mathrm{the} \mathrm{recruitment} \mathrm{of} \mathrm{L.} \mathrm{forbesi,} \mathrm{Pierce}$ et al. (1994b) found the squid recruited throughout the year in Scottish waters, with peaks in April and November (Collins et al., 1997). Small-sized L. forbesi $(<15 \mathrm{~cm}$ ML) dominated catches of $L$. forbesi during autumn in both Scottish and French survey cruises, accounting for $75 \%$ and $70 \%$ (by number) of total catch, respectively. This corresponds to the main period of recruitment of $L$. forbesi in autumn as proposed by Collins et al. (1999).

Both common trends in the optimum DFA model indicated a different pattern of Loligo spp. abundance variation in the north and south of the species' ranges in the northeast Atlantic (Fig. 4). The first trend reflected a general increase of squid abundance in the north regions. The second trend indicated a general decrease of squid abundance in the south regions. Note however that we did not find that $L$. forbesi tended to be replaced by L. vulgaris in the south: both species showed similar trends in Portuguese waters, so this analysis provides no evidence that interspecific competition could explain the trends.

The potential contribution of SST as an explanatory variable is evident in several studies on distribution pattern and abundance of Loligo squid (Waluda and Pierce, 1998; Bellido et al., 2001; Pierce and Boyle, 2003; Zuur and Pierce, 2004). In this study, relationships of squid abundance series with autumn SST suggest similar patterns in the north and the south (Table 4). Thus abundance of (small) L. forbesi in the north of its range, and L. vulgaris in the south of its range, were higher in years 
with lower autumn SST, while in the Celtic sea, (small) L. forbesi abundance was positively related to autumn SST.

It could be suggested that the different relationships with SST shown by L. forbesi in different areas reflect the fact that it competes with L. vulgaris in the Celtic Sea but experiences no such competition further north. This interpretation is broadly supported by life history data. In Spanish and Portuguese waters, evidence from the early 1990s suggests that both species breed during December to February (Guerra and Rocha, 1994; Moreno et al., 1994). In the English Channel, data on the proportion of both species in fishery landings during 1992 to 1995 suggest that the life-cycles of the two species are out of phase (Robin and Boucaud-Camou, 1995) - which could be a mechanism for reducing competition.

The idea that L. forbesi and L. vulgaris compete in the English Channel is supported by stock assessments carried out on cohorts 1993 to 1995 where an opposite trend in recruitment estimates was observed (Royer et al., 2002). However, in 1996 low recruitment was observed in both species and also in Sepia officinalis (Royer, 2002) which suggest that environmental conditions in this area can be unfavourable to all cephalopods.

The North Atlantic Oscillation (NAO) index measures the difference between sea level pressures in Iceland and the Azores, which could indicate the variation of westerly winds in the north Atlantic (Hurrell, 1995). Sims et al. (2001) showed that migration of $L$. forbesi in the English Channel occurred earlier when the water temperature in the preceding month was higher, which corresponded to the warm (positive) phase of NAO. Zuur and Pierce (2004) showed that NAO index was significantly related to the abundance of L. forbesi in the months of August November in the northeast coastal of Scotland (ICES division IVa). In our study, which focussed on abundance in the autumn, only abundance of small L. forbesi in the Scotland was significantly related to the winter NAO index (Table 4). This could imply that large-scale variability of climatic conditions has a less important effect on squid abundance than local thermal changes (SST), particularly in south region.

The monthly SST series were compared with the two common trends of squid abundance (mainly from autumn) to examine the lagged SST effect. Common trend 1 of squid abundance was positively correlated to the SST in spring (February - May) and autumn (August - November) (Table 5). Common trend 2 of squid abundance was negatively correlated to the SST in spring (February - June) (Table 5). The 
significant correlation between SST in spring and squid abundance in autumn could indicate the potential effect of SST on the squid recruitment success during early life history.

The abundance of Illex argentinus has been suggested to correlate to the variability of surface oceanography in the inferred hatching grounds during the early life history stage (Waluda et al., 2001), though the mechanisms by which environmental variables influence squid recruitment dynamics are still unclear. However, the influence of spring SST on squid abundance in autumn was different in north and south regions, which may imply different adaptations of the same squid species to the habitat in different regions.

Squid are short-lived animals, and are sensitive to the environmental variability. The DFA model contained SST and winter NAO series as explanatory variables was calculated to be the optimal model in this study (Table 3). This is similar to the analysis of common trends in monthly coastal squid (Loligo spp.) abundance in Scottish waters (Zuur and Pierce, 2004). This result suggested that variation of squid abundance could be affected by local SST variation resulting from large-scale variation of (winter) NAO index. In southern hemisphere, variation of commercial squid stocks was suggested to be influenced by the Southern Oscillation Index (SOI) and Trans Polar Index (TPI), via local SST as connecting factor (Waluda et al., 2004). In this study, SST series showed a positive correlation with common trend 1 at a lag of 1-2 yrs, and negative correlations with common trend 2 at lags of 1-3 yrs (Fig. 7). However, no significant correlation was found between the winter NAO index and either common trend. The lagged effect of yearly SST on squid abundance may serve as a proxy of suitable oceanographic conditions in the north Atlantic. It should be noted that no significant cross-correlation was detected between (winter) NAO and SST over the period studied.

As noted by Anon. (2002), comparisons between Northeast Atlantic and Mediterranean cephalopod fishery production figures indicate that cephalopod landings from the ICES (Atlantic) area have increased in the last decade while Mediterranean landings have been decreasing. Thus it is of interest to compare our results with data for the Mediterranean. Some shorter ( $9-13 \mathrm{yrs})$ time series of trawl survey data were available for Italian waters (PJ, SR, AM and LO-R, unpubl. data; see Table 6). We compared the abundance of Loligo spp. from Italian waters with the calculated common trends. Only a significantly positive correlation between L. forbesi in the Ligurian Sea and common trend 2 was noted, which represents a general pattern 
of decreasing abundance in the south region. A positive correlation between $L$. vulgaris in Sicilian Channel and trend 1, and a negative correlation between $L$. forbesi in Sicilian Channel and trend 2 were noted, though neither was statistically significant. The variability of species abundance and oceanographic conditions in the Mediterranean Sea could be affected by the NAO episodes. The landings of commercial species in the northwest Mediterranean Sea have been suggested to be influenced by local (river discharges, wind conditions) and global (NAO) environmental conditions (Lloret et al., 2001). The substitution of the original cold transitional layer water (below $600-700 \mathrm{~m} ; 12.8^{\circ} \mathrm{C} ; 38.4 \mathrm{ppt}$ ) for the invasion of the Transitional Eastern Mediterranean Deep water (slightly warmer, $13.53^{\circ} \mathrm{C}$, but much more dense water), which originated some years ago in the Eastern Mediterranean, may influence the oceanographic conditions in the Strait of Sicily, and is going to interact with the local fauna and have effects on the life cycle of the species. Thus, the present analysis provides only limited evidence that abundance trends seen in the Atlantic may be similar to those in at least parts of the Mediterranean Sea.

\section{Acknowledgements}

Data on squid abundance were extracted from national fishery and survey databases. The new analysis reported here was supported by the European Commission as part of the CEPHSTOCK project (Q5CA-2002-00962). Chih-Shin Chen was supported by a grant from the National Science Council, Republic of China (Taiwan) (Contract No. NSC 42003F).

\section{References}

Anon., 2002. Report of the Working Group on Cephalopod Fisheries and Life History. International Council for the Exploration of the Sea CM 2002/G:02.

Bakun, A., Csirke, J., 1998. Environmental processes and recruitment variability. In: Rodhouse, P.G., Dawe, E.G. O'Dor R.K. (Eds.), Squid Recruitment Dynamics. The genus Illex as a model, the commercial Illex species and influence on variability. FAO Fisheries Technical Paper No. 376. FAO, Rome, pp. 105-124.

Bellido, J.M., Pierce, G.J., Wang, J., 2001. Modelling intra-annual variation in abundance of squid Loligo forbesi in Scottish waters using generalized additive models. Fish. Res. 52, 23-39.

Boyle, P.R., Pierce, G.J., 1994. Fishery biology of Northeast Atlantic squid: an overview. Fish. Res. 21, 1-15.

Collins, M.A., Pierce, G.J., Boyle, P.R., 1997. Population indices of reproduction and 
recruitment in Loligo forbesi (Cephalopod: Loliginidae) in Scottish and Irish waters. J. Appl. Ecol. 34, 778-786.

Collins, M.A., Boyle, P.R., Pierce, G.J., Key, L.N., Hughes, S.E., Murphy, J., 1999. Resolution of multiple cohorts in the Loligo forbesi population from the west of Scotland. ICES J. Mar. Sci. 56, 500-509.

Cunha, M.M., Moreno, A., 1994. Recent trends in the Portuguese squid fishery. Fish. Res. 21, 231-241.

Denis, V., Lejeune, J., Robin, J.-P., 2002. Spatio-temporal analysis of commercial trawler data using General Additive models: patterns of Loliginid squid abundance in the north-east Atlantic. ICES J. Mar. Sci. 59, 633-648.

Guerra, A., Rocha, F., 1994. The life history of Loligo vulgaris and Loligo forbesi (Cephalopoda: Loliginidae) in Galician waters (NE Spain). Fish. Res. 21, 43-70.

Guerra, A., Sánchez, P., Rocha, F., 1994. The Spanish fishery for Loligo: recent trends. Fish. Res. 21, 217-230.

Hurrell, J.W., 1995. Decadal trends in the North Atlantic Oscillation: Regional temperatures and precipitation. Science 269, 676-679.

Lloret, J., Lleonart, J., Solé, I., Fromentin, J.-M., 2001. Fluctuations of landings and environmental conditions in the north-western Mediterranean Sea. Fish. Oceanogr. 10, 33-50.

Moreno, A., Cunha, M.M., Pereira J.M.F., 1994. Population biology of veined squid (Loligo forbesi) and European squid (Loligo vulgaris) from the Portuguese coast. Fish. Res. 21, 71-86.

Pierce, G.J., Boyle, P.R., 2003. Empirical modelling of interannual trends in abundance of squid (Loligo forbesi) in Scottish waters. Fish. Res. 59, 305-326.

Pierce, G.J., Boyle, P.R., Hastie, L.C., Key, L., 1994a. The life history of Loligo forbesi (Cephalopoda: Loliginidae) in Scottish waters. Fish. Res. 21, 17-42.

Pierce, G.J., Boyle, P.R., Hastie, L.C., Shanks, A.M., 1994b. Distribution and abundance of the fished population of Loligo forbesi in UK waters: analysis of fishery data. Fish. Res. 21, 193-216.

Pierce, G.J., Bailey, N., Stratoudakis, Y., Newton, A., 1998. Distribution and abundance of the fished population of Loligo forbesi in Scottish waters: analysis of research cruise data. ICES J. Mar. Sci. 55, 14-33.

Quinn, G.P., Kenough, M.J., 2002. Experimental Design and Data Analysis for Biologists. Cambridge University Press, Cambridge.

Reynolds, R.J., Smith, T.M., 1994. Improved global sea surface temperature analysis using optimal interpolation. J. Climate 7, 929-948.

Robin, J.P., Boucaud-Camou, E. 1995. Squid catch composition in the English Channel bottom trawl fishery: proportion of Loligo forbesi and Loligo vulgaris in 
the landings and length-frequencies of both species during the 1993-1994 period. ICES CM 1995/K:36, International Council for the Exploration of the Sea.

Robin, J.-P., Denis, V., 1999. Squid stock fluctuations and water temperature: temporal analysis of English Channel Loliginidae. J. Appl. Ecol. 36, 101-110.

Royer J., 2002. La modélisation des stocks de céphalopodes de Manche. PhD thesis, Université de Caen, France, 242pp.

Royer J., Peries P., Robin J.P., 2002. Stock assessments of English Channel Loliginid squid: updated depletion methods and new analytical methods. ICES J. Mar. Sci., 59, 445-457.

Shaw, P.W., Pierce, G.J., Boyle, P.R., 1999. Subtle population structuring within a highly vagile marine invertebrate, the veined squid Loligo forbesi, demonstrated with microsatellite DNA markers. Mol. Ecol. 8, 407-417.

Sims, D.W., Genner, M.J., Southward, A.J., Hawkins, S.J., 2001. Timing of squid migration reflects the North Atlantic climate variability. Proc. R. Soc. Lond. B 268, 2607-2611.

Waluda, C.M., Pierce, G.J., 1998. Temporal and spatial patterns in the distribution of squid (Loligo spp.) in UK waters. S. Afr. J. Mar. Sci. 20, 323-336.

Waluda, C.M., Rodhouse, P.G., Podestá, G.P., Trathan, P.N., Pierce, G.J., 2001. Surface oceanography of the inferred hatching grounds of Illex argentinus (Cephalopoda: Ommastrephidae) and influences on recruitment variability. Mar. Biol. 139, 671-679.

Waluda, C.M., Trathan, P.N., Rodhouse, P.G., 2004. Synchronicity in southern hemisphere squid stocks and the influence of the Southern Oscillation and Trans Polar Index. Fish. Oceanogr. 13, 255-266.

Wang, J., Pierce, G.J., Boyle, P.R., Denis, V., Robin, J.-P., Bellido, J.M., 2003. Spatial and temporal patterns of cuttlefish (Sepia officinalis) abundance and environmental influences - a case study using trawl fishery data in French Atlantic coastal, English Channel, and adjacent waters. ICES J. Mar. Sci. 60, 1149-1158.

Young, I.A.G., Pierce, G.J., Daly, H.I., Santos, M.B., Key, L.N., Bailey, N., Robin, J.-P., Bishop, A.J., Stowasser, G., Nyegaard, M., Cho, S.K., Rasero, M., Pereira, J.M.F., 2004. Application of depletion methods to estimate stock size in the squid Loligo forbesi in Scottish waters (UK). Fish. Res. 69, 211-227.

Young, I.A.G., Pierce, G.J., Stowasser, G., Santos, M.B., Wang, J., Boyle, P.R., Shaw, P.W., Bailey, N., Tuck, I., Collins, M.A., In Press. The Moray Firth directed squid fishery. Fish. Res.

Zuur, A.F., Fryer, R.J., Jolliffe, I.T., Dekker, R., Beukema, J.J., 2003a. Estimating common trends in multivariate time series using dynamic factor analysis. Environmetrics 14, 665-685. 
Zuur, A.F., Tuck, I.D., Bailey, N., 2003b. Dynamic factor analysis to estimate common trends in fisheries times series. Can. J. Fish. Aquat. Sci. 60, 542-552.

Zuur, A.F., Pierce, G.J., 2004. Common trends in northeast Atlantic squid time series. J Sea Res. 52, 57-72. 


\section{Table 1}

The time series of squid abundance data used in this study.

\begin{tabular}{|c|c|c|c|c|}
\hline Series label & Country & Data source & Target species & Period \\
\hline Sc_Lf_S & Scotland & Survey cruise & $\begin{array}{l}\text { Loligo forbesi } \\
\text { (Small-sized) }\end{array}$ & $1977-2003$ \\
\hline Sc_Lf_L & Scotland & Survey cruise & $\begin{array}{l}\text { L. forbesi } \\
\text { (Large-sized) }\end{array}$ & $1977-2003$ \\
\hline Sc_LPUE & Scotland & $\begin{array}{l}\text { Commercial } \\
\text { trawling }\end{array}$ & Loligo spp. & $1977-2003$ \\
\hline Fr_Lf_S & France & Survey cruise & $\begin{array}{l}\text { L. forbesi } \\
\text { (Small-sized) }\end{array}$ & $1987-2003$ \\
\hline Fr_Lf_L & France & Survey cruise & $\begin{array}{l}\text { L. forbesi } \\
\text { (Large-sized) }\end{array}$ & $1987-2003$ \\
\hline Fr_Lv & France & Survey cruise & L. vulgaris & $1987-2003$ \\
\hline Fr_LPUE & France & $\begin{array}{l}\text { Commercial } \\
\text { trawling }\end{array}$ & Loligo spp. & 1989-2002 \\
\hline Pt_Lf & Portugal & Survey cruise & L. forbesi & 1990-2002 \\
\hline Pt_Lv & Portugal & Survey cruise & L. vulgaris & 1990-2002 \\
\hline Pt_LPUE & Portugal & $\begin{array}{l}\text { Commercial } \\
\text { trawling }\end{array}$ & Loligo spp. & 1988-1996 \\
\hline
\end{tabular}




\section{Table 2}

The types of dynamic factor models used in the analysis. ( $\boldsymbol{R}$ is the error covariance matrix)

\begin{tabular}{lll}
\hline Type & Model & $R$ \\
\hline 1 & CPUE series $=$ constant $+M$ common trends + noise & diagonal \\
2 & CPUE series $=$ constant $+M$ common trends + explanatory & diagonal \\
& variables + noise & non-diagonal \\
3 & CPUE series $=$ constant $+M$ common trends + noise & \\
& & CPUE series $=$ constant $+M$ common trends + explanatory \\
4 & variables + noise & \\
\hline
\end{tabular}




\section{Table 3}

AIC values obtained from DFA on the CPUE and LPUE time series. $M$ is the number of common trends. Models are labelled following Table 1, and using a, b, and c to denote the fitting of 1,2 and 3 common trends respectively. The best model is indicated in bold face.

\begin{tabular}{llll}
\hline Model & M & AIC & Explanatory variable \\
\hline $1 \mathrm{a}$ & 1 & 493.590 & \\
$1 \mathrm{~b}$ & 2 & 492.453 & \\
$1 \mathrm{c}$ & 3 & 489.988 & \\
$1 \mathrm{~d}$ & 4 & 507.048 & \\
$\mathrm{2a}$ & 1 & 506.107 & SST \\
$2 \mathrm{~b}$ & 2 & 557.623 & SST \\
$2 \mathrm{c}$ & 1 & 520.415 & NAO \\
$2 \mathrm{~d}$ & 2 & 497.516 & NAO \\
$2 \mathrm{e}$ & 3 & 499.934 & NAO \\
$2 \mathrm{f}$ & 1 & 490.993 & SST \& NAO \\
$2 \mathrm{~g}$ & 2 & 497.039 & SST \& NAO \\
$3 \mathrm{a}$ & 1 & 483.319 & \\
$3 \mathrm{~b}$ & 2 & 489.021 & SST \\
$4 \mathrm{a}$ & 1 & 496.575 & NAO \\
$4 \mathrm{~b}$ & 1 & 473.450 & NAO \\
$4 \mathrm{c}$ & 2 & 481.782 & SST \& NAO \\
$4 \mathrm{~d}$ & 1 & 418.741 & SST \& NAO \\
$4 \mathrm{e}$ & 2 & $\mathbf{4 0 1 . 9 6 1}$ & SST \& NAO \\
$4 \mathrm{f}$ & 3 & 432.036 &
\end{tabular}




\section{Table 4}

Estimated regression parameters and $t$ values for the explanatory variables (SST \& NAO series). Significant values are shown in bold face. Series labels are as described in the legend to Table 1.

\begin{tabular}{lccccc}
\hline Series label & \multicolumn{2}{l}{ SST } & & \multicolumn{2}{l}{ NAO } \\
\cline { 2 - 3 } \cline { 5 - 6 } & Estimate & t-value & & Estimate & t-value \\
\hline Sc_Lf_S & $\mathbf{- 0 . 7 0}$ & $\mathbf{- 4 . 0 7}$ & & $\mathbf{0 . 3 3}$ & $\mathbf{2 . 2 5}$ \\
Sc_LF_L & -0.12 & -0.54 & & 0.01 & 0.04 \\
Sc_LPUE & 0.13 & 0.72 & & 0.26 & 1.84 \\
Fr_Lf_S & $\mathbf{0 . 7 5}$ & $\mathbf{3 . 7 6}$ & & -0.06 & -0.34 \\
Fr_Lf_L & 0.32 & 1.59 & & 0.01 & 0.07 \\
Fr_Lv & -0.02 & -0.11 & & 0.13 & 0.87 \\
Fr_LPUE & -0.13 & -0.49 & & 0.15 & 0.67 \\
Pt_Lf & -0.40 & -1.70 & & -0.35 & -1.69 \\
Pt_Lv & $\mathbf{- 0 . 7 1}$ & $\mathbf{- 2 . 4 8}$ & & -0.26 & -1.04 \\
\hline
\end{tabular}




\section{Table 5}

The Spearman's correlation between common trends of squid abundance and monthly SST. Significant values $(P<0.05)$ are shown in bold face. (n: sample size)

\begin{tabular}{lcccccc}
\hline & & \multicolumn{2}{l}{ Trend 1 } & & \multicolumn{2}{l}{ Trend 2 } \\
\cline { 3 - 4 } \cline { 6 - 7 } Variables & $\mathrm{n}$ & Spearman $\mathrm{r}$ & $P$ value & & Spearman $\mathrm{r}$ & $P$ value \\
\hline SST_Jan & 21 & 0.217 & 0.345 & & -0.409 & 0.065 \\
SST_Feb & 21 & $\mathbf{0 . 5 0 0}$ & $\mathbf{0 . 0 2 1}$ & & $\mathbf{- 0 . 5 2 6}$ & $\mathbf{0 . 0 1 4}$ \\
SST_Mar & 21 & $\mathbf{0 . 4 7 2}$ & $\mathbf{0 . 0 3 1}$ & & $\mathbf{- 0 . 5 4 5}$ & $\mathbf{0 . 0 1 1}$ \\
SST_Apr & 21 & $\mathbf{0 . 5 4 4}$ & $\mathbf{0 . 0 1 1}$ & & $\mathbf{- 0 . 5 7 6}$ & $\mathbf{0 . 0 0 6}$ \\
SST_May & 21 & $\mathbf{0 . 5 0 0}$ & $\mathbf{0 . 0 2 1}$ & & $\mathbf{- 0 . 7 2 8}$ & $\mathbf{0 . 0 0 0}$ \\
SST_Jun & 21 & 0.235 & 0.305 & & $\mathbf{- 0 . 4 7 6}$ & $\mathbf{0 . 0 2 9}$ \\
SST_Jul & 21 & 0.368 & 0.100 & & -0.357 & 0.112 \\
SST_Aug & 21 & $\mathbf{0 . 4 5 7}$ & $\mathbf{0 . 0 3 7}$ & & -0.335 & 0.138 \\
SST_Sep & 21 & $\mathbf{0 . 7 9 1}$ & $\mathbf{0 . 0 0 0}$ & & -0.330 & 0.144 \\
SST_Oct & 21 & $\mathbf{0 . 7 4 2}$ & $\mathbf{0 . 0 0 0}$ & & -0.423 & 0.056 \\
SST_Nov & 21 & $\mathbf{0 . 6 0 9}$ & $\mathbf{0 . 0 0 3}$ & & -0.198 & 0.390 \\
SST_Dec & 21 & 0.233 & 0.309 & & -0.202 & 0.380 \\
\hline
\end{tabular}




\section{Table 6}

Spearman's correlations between common trends of squid abundance in the NE Atlantic and Loligo abundance from trawl surveys in Italian waters (Mediterranean Sea). (It_Lf_Sic \& It_Lv_Sic: Loligo forbesi and L. vulgaris abundance estimated from Italian GRUND survey in the Sicilian Channel during 1985-2003, respectively; It_Lf_Lig \& It_Lv_Lig: L. forbesi and L. vulgaris abundance estimated from Italian GRUND survey in the Ligurian Sea during 1994-2003, respectively. Squid abundance was standardised using mean and standard deviation. Significant values $(P<0.05)$ are shown in bold face. n: sample size)

\begin{tabular}{lcccccc}
\hline & & \multicolumn{2}{c}{ Trend 1} & & \multicolumn{2}{c}{ Trend 2 } \\
\cline { 3 - 4 } \cline { 6 - 7 } Series & $\mathrm{n}$ & Spearman $\mathrm{r}$ & $P$ value & & Spearman $\mathrm{r}$ & $P$ value \\
\hline It_Lf_Sic & 13 & -0.297 & 0.325 & & -0.484 & 0.094 \\
It_Lv_Sic & 13 & 0.478 & 0.098 & & 0.225 & 0.459 \\
It_Lf_Lig & 9 & 0.100 & 0.797 & & $\mathbf{0 . 7 2 0}$ & $\mathbf{0 . 0 2 9}$ \\
It_Lv_Lig & 9 & 0.083 & 0.831 & & 0.117 & 0.765 \\
\hline
\end{tabular}




\section{FIGURE LEGENDS}

Figure 1. The locations of trawling survey catches (pooled by ICES rectangle) by Scottish (pink circles), French (blue circles), and Portuguese (red circles) research vessels during autumn. All data from French, and Portuguese survey cruise were used, while only data for areas IVa and VIa were used in the case of Scottish trawling surveys. The selected localities for sea surface temperature (SST) series are also presented (light green circles).

Figure 2. Standardised CPUE and LPUE time series for survey and fishery data on squid from Scotland, France and Portugal. (Series labels are as in Table 1)

Figure 3. Standardised SST and NAO index time series. The SST data were extracted from the NCAR SST database. The "north" SST series was extracted for ICES rectangle $40 \mathrm{E} 4\left(5^{\circ} 5^{\prime} \mathrm{W}, 55^{\circ} 75^{\prime} \mathrm{N}\right)$, and the "south" SST series extracted from ICES rectangle $06 \mathrm{E} 0\left(9^{\circ} 5^{\prime} \mathrm{W}, 38^{\circ} 75^{\prime} \mathrm{N}\right)$.

Figure 4. Results for dynamic factor analysis. The upper row of figures contains the first common trend (left), and the canonical correlations (right) between the original squid abundance series and this common trend. The lower rows contain the graphs for the second common trend and the canonical correlations between the original squid abundance series and this common trend. Series labels are as in Table 1.

Figure 5. Fitted values (lines) and standardised observed values for CPUE and LPUE series. The labels for each graph are as in Table 1.

Figure 6. The frequency distribution of residuals for 9 squid time series used in the dynamic factor analysis model.

Figure 7. Cross-correlation functions between common trends of squid abundance and environmental variables: SST at ICES rectangle $40 \mathrm{E} 4\left(5^{\circ} 5^{\prime} \mathrm{W}, 55^{\circ} 75^{\prime} \mathrm{N}\right)$, and winter NAO index. Positive lag ( 0 to 5 years) indicates environmental variable leading squid abundance trend, and negative lag ( 0 to -5 years) indicates squid abundance trend leading environmental variable. Dashed lines are $95 \%$ confidence intervals. 
Figure 1.

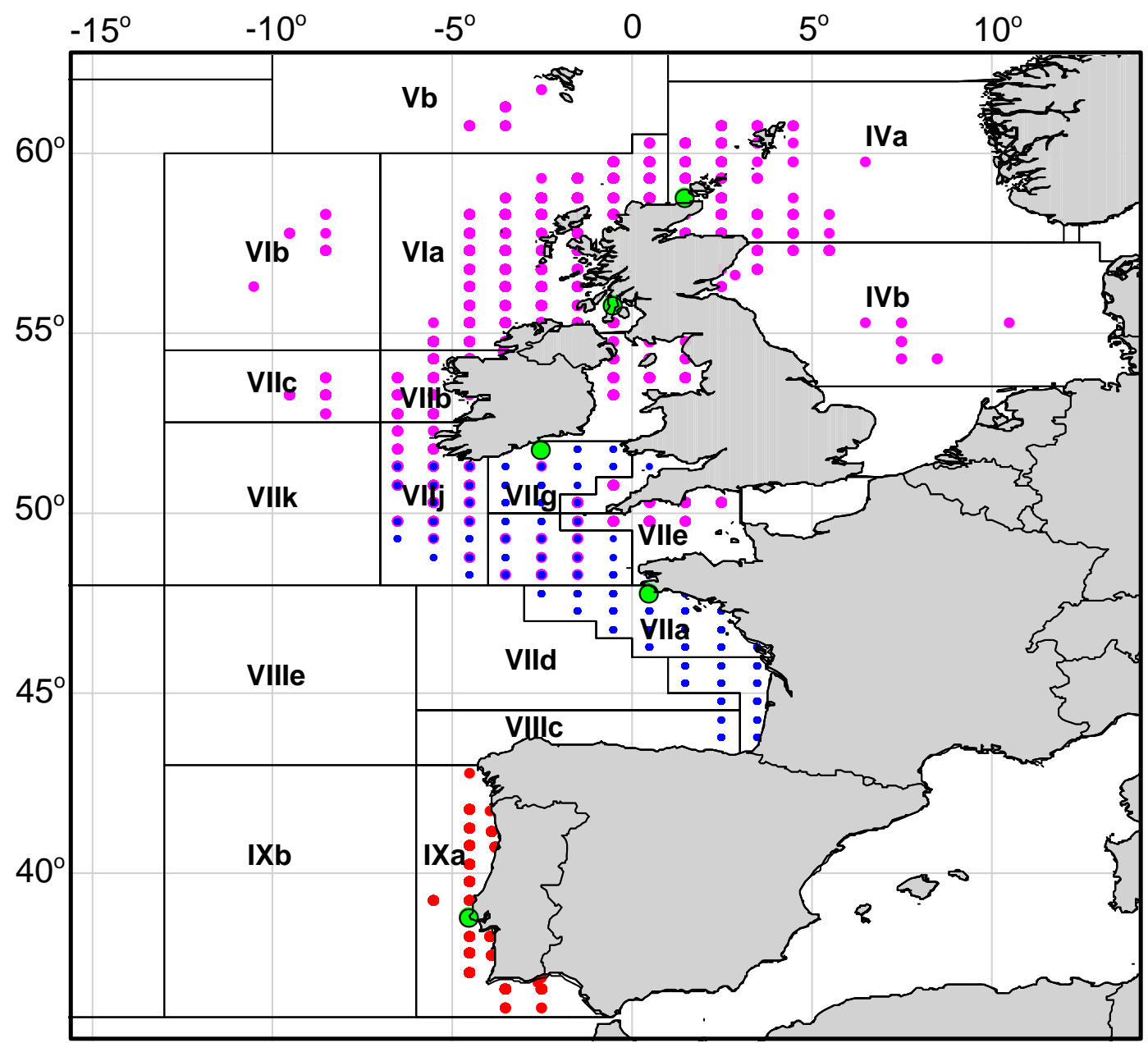


Figure 2.

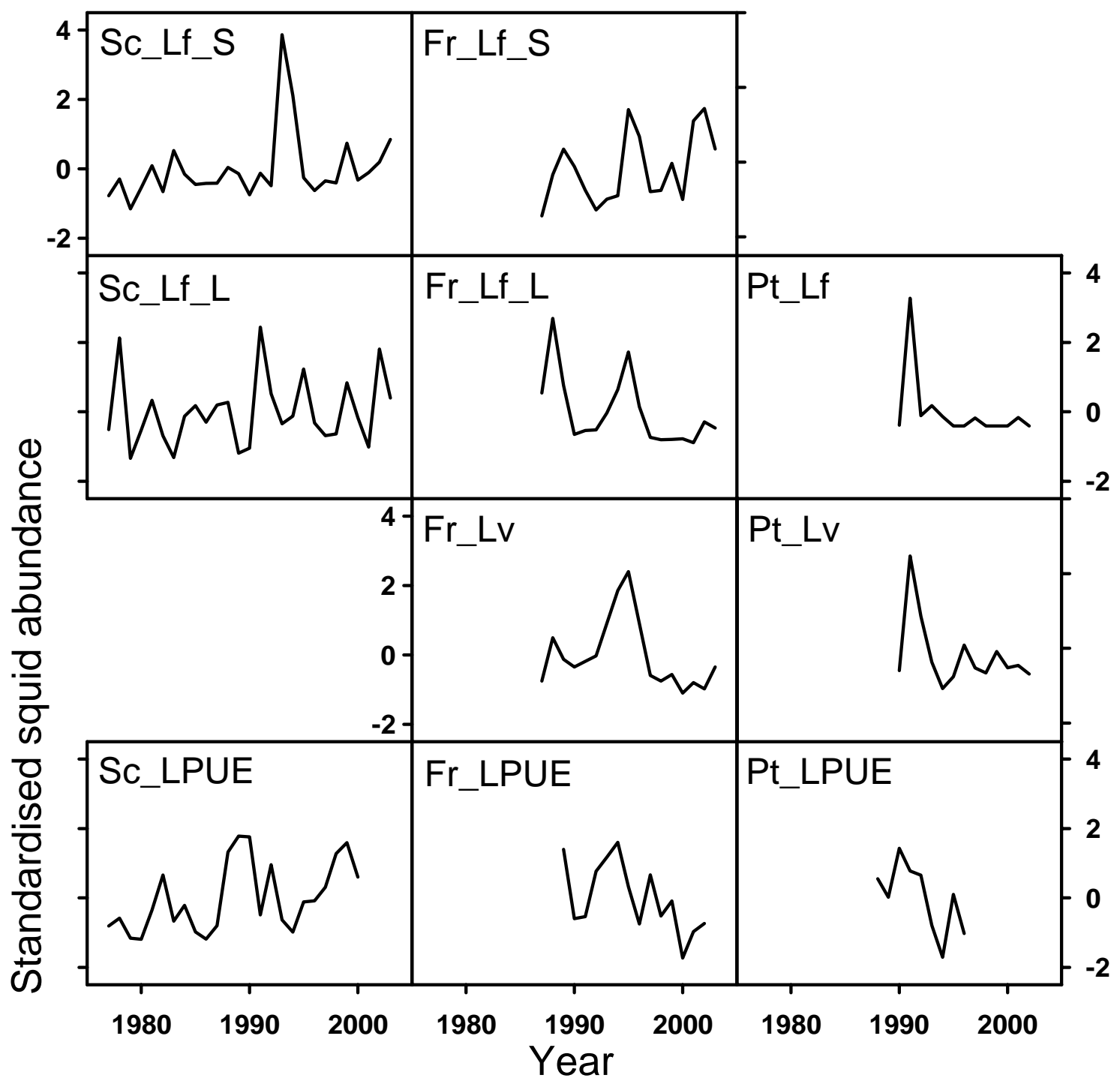


Figure 3.

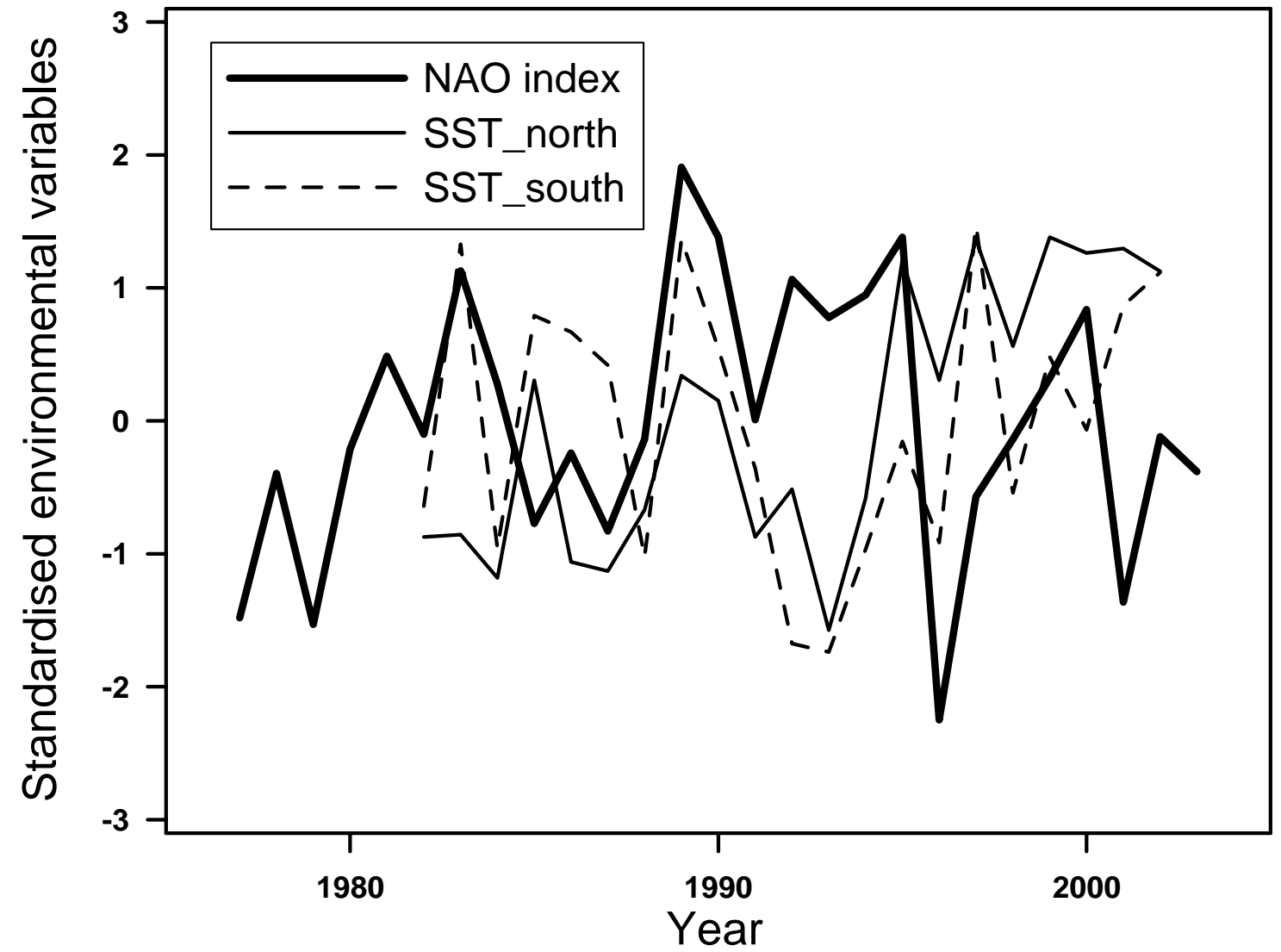


Figure 4.

Trend 1
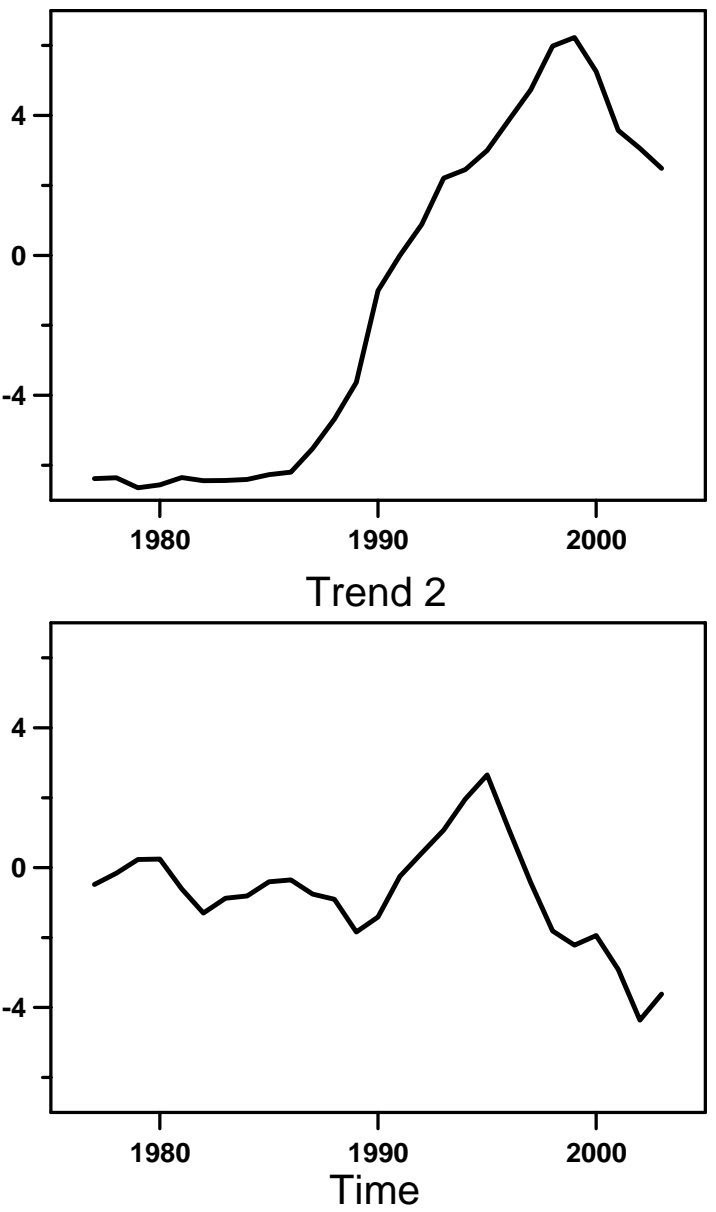

Canonical correlation trend 1

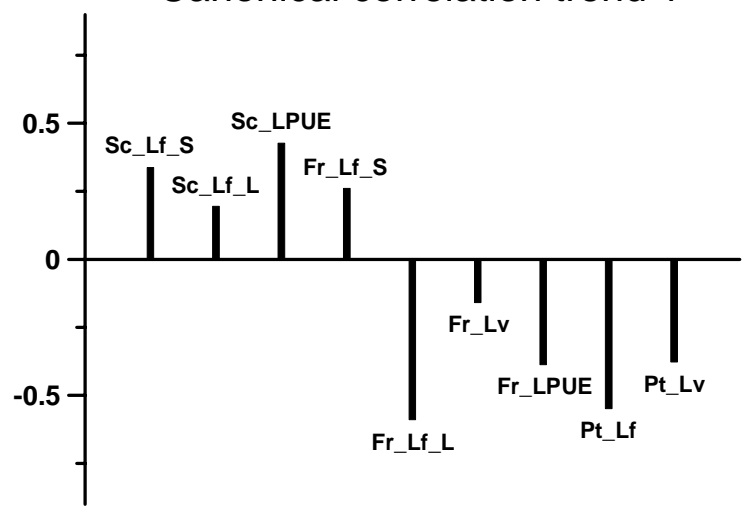

Canonical correlation trend 2

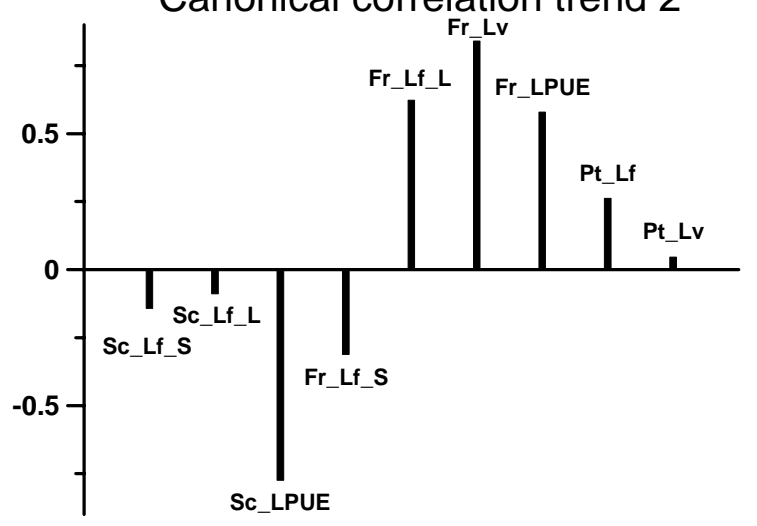


Figure 5.

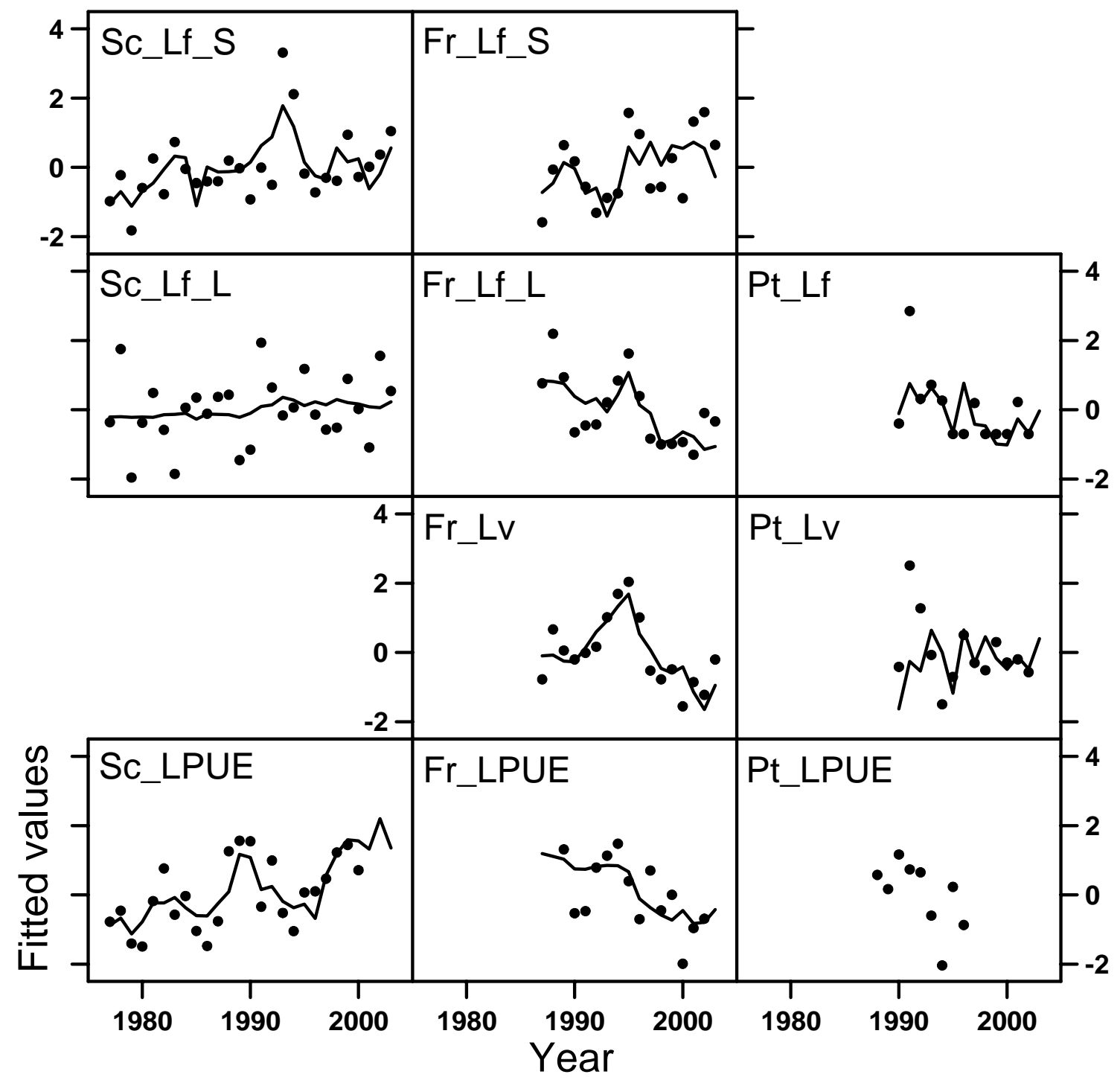


Figure 6.
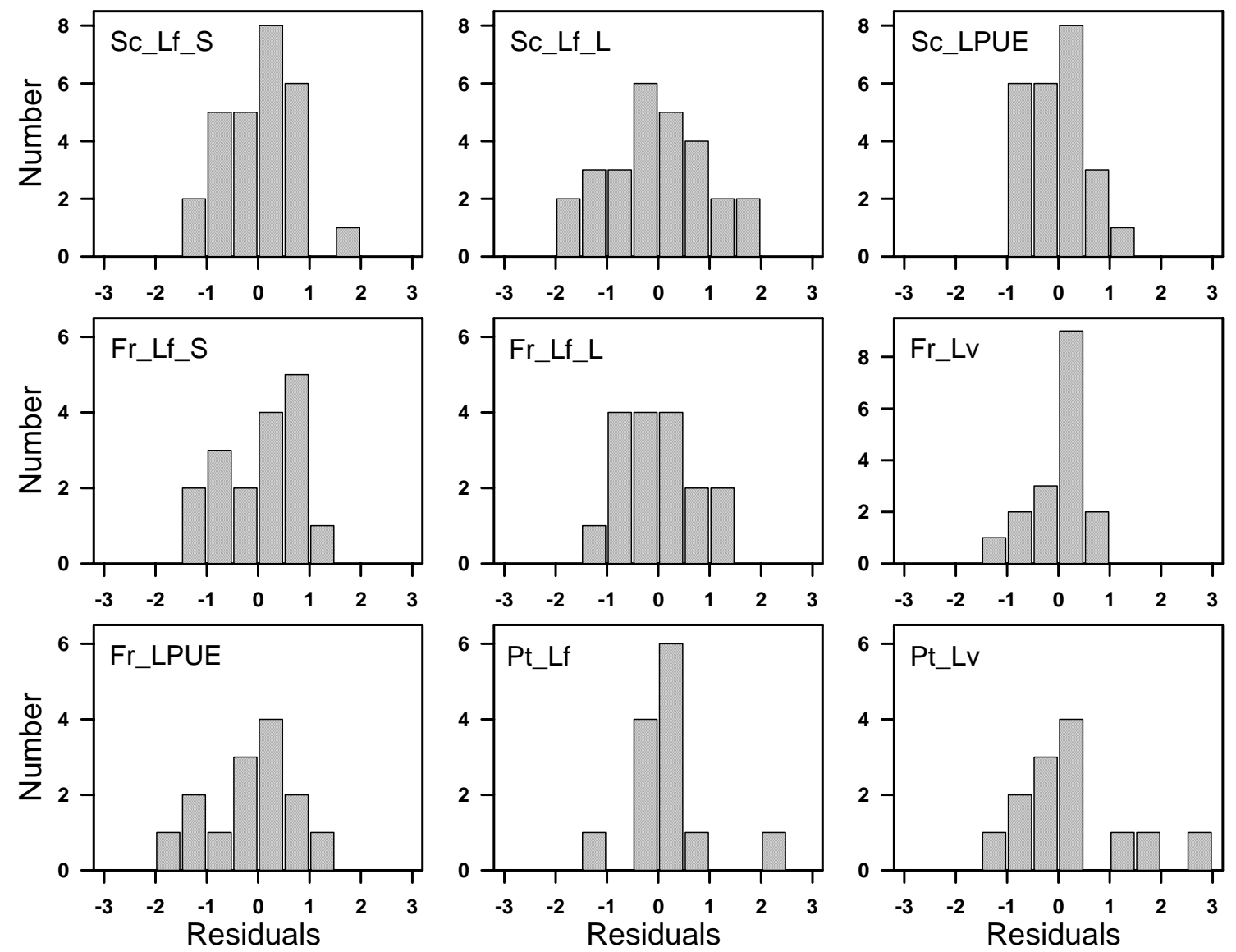
Figure 7.
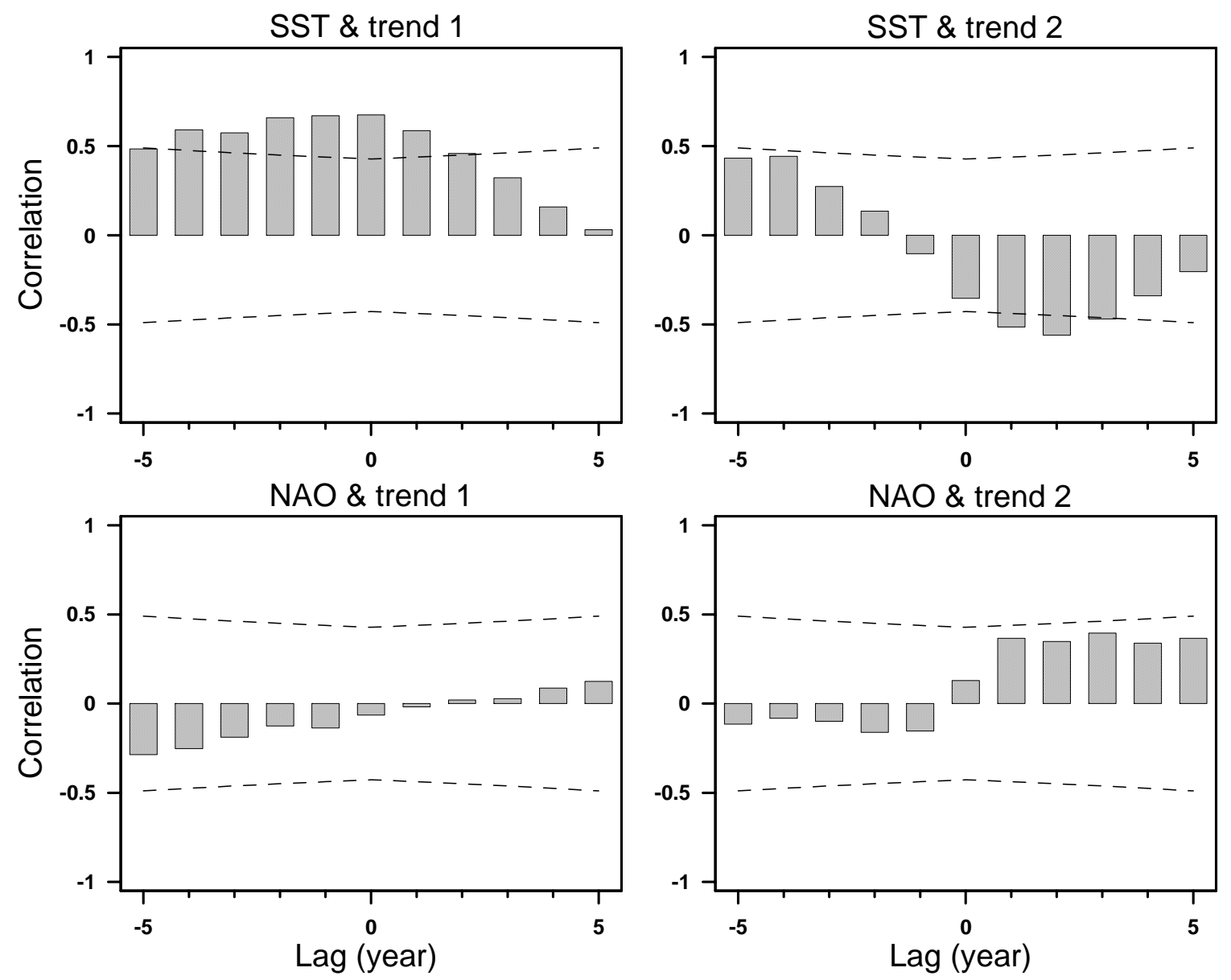